\title{
XL Plus Men - New Data on Garment Sizes
}

\author{
Simone MORLOCK*, Andreas SCHENK, Anke KLEPSER, Andreas SCHMIDT \\ Hohenstein Institut für Textilinnovation gGmbH, Boennigheim, Germany
}

DOI: $10.15221 / 16.255 \quad$ http://dx.doi.org/10.15221/16.255

\begin{abstract}
As part of the R\&D project "Plus sizes men" (IGF $17460 \mathrm{~N}$ ) the special body shapes of men with body volumes and circumferences above standard garment sizes have been analyzed. New sizing charts for men with plus sizes have been generated, specific body shapes were identified and optimized basic patterns have been developed.
\end{abstract}

Lack of physical data for developing clothing in plus sizes: The demand from retailers for plus size fashion is continuously growing. The market share of large menswear on the market has increased significantly. Although there is a need for well-fitting plus size clothes, no reliable anthropometric data was available so far. For that reason, the "Plus sizes men" research project was initiated in order to develop reliable sizing charts for men XL plus. A sizing survey was carried out using 3D scanner technology. Within the project, 664 men with chest circumferences of $120 \mathrm{~cm}$ up to $175 \mathrm{~cm}$ were scanned.

New sizing chart for menswear, sizes 60 to 78: On basis of the survey results, new sizing charts for menswear were developed covering the German sizes 60 to 78 and describing five figure types as well as five body height types. The sizing chart "Plus sizes men" is linked to the SizeGERMANY sizing system, in order to achieve the widest possible acceptance on the market. Furthermore, time target group specific measurements have been measured and analyzed.

Definition of morphotypes: Body shape variety of big sizes is huge. Therefore, shape analyses were performed and morphotypes, e.g. specific abdominal forms of men, were defined.

3D body models as basis for fit mannequins, 3D pattern construction and simulation: On the basis of the new body measurements, virtual 3D body models were generated. These 3D models represent target group specific average body shapes, like the stomach shape, for individual sizes.

Optimized basic patterns based on 3D scan data: Optimized basic patterns for trousers and jackets were developed based on the 3D body models. These 3D models - available as polygon mesh - have to be converted into 3D NURBS planes to be flattened. After flattening, optimized pattern geometry can be reproduced. By translating 3D body geometric information into 2D pattern, the fit can be significantly improved.

Keywords: 3D body scanning, sizing survey, plus sizes men, size charts, 3D body models, fit, pattern

\section{Introduction}

The retailers demand for plus size fashion is growing constantly. Juxtaposing German men's sizing survey from 1980 [1] and SizeGERMANY 2009 [2] the results indicate that the market share of large menswear has increased significantly. Figure 1 shows a clear movement from small and middle sizes to big sizes. Chest circumferences increased $7.3 \mathrm{~cm}$ on average. This corresponds to about a difference of two sizes.

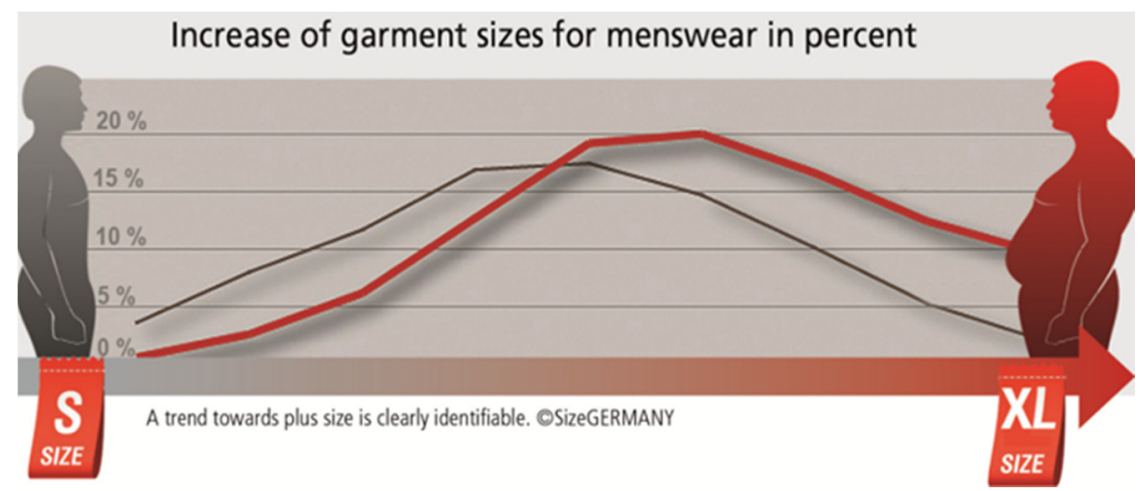

Fig. 1. Comparing the German sizing surveys results from 1980 and 2009

*s.morlock@hohenstein.de; +49- 7143-271-305; www.hohenstein.de 
However, there were no existing standardized sizing charts for plus sizes men at that time [3][4]. Reliable anthropometric data was missing, too. Although it is well known that, "the anthropometric data will generate meaningful size distribution which in turn will provide accurate pattern cutting and satisfactory fit for the consumers" and will allow cost-effective garment production as well [5]. Without a reliable data base, garment producers had to work with an idealized picture of their customers. Based on the proportions of the middle sizes, supplemented with company know-how, body measurements for the big sizes were extrapolated according to company specific grading rules [3]. Due to the missing size standard, a tremendous variance of sizes on the market has been arisen.

In 2009 public founded research project "plus sizes women” (,Starke Figuren“ IGF 15144 BG) filled the gap regarding the female population. [6] Subsequently, German clothing industry required an analogous solution for men's plus sizes. Therefore, research project "plus sizes men" ("Große Größen Männer" IGF 17460 N) [7] was conducted in order to analyze the specific physical appearance of men with big circumferences and volumes beyond the regular garment sizes.

\section{Methods}

\subsection{Realization of the sizing survey}

Main requirement of the project success was a reasonable amount of target group body data. Therefore, a sizing survey was carried out covering especially men with sizes larger than German size 56. That corresponds to chest circumference greater $112 \mathrm{~cm}$. 3D-Bodyscanner Vitus Smart XXL (see figure 2) was utilized at one location in the south-western part of Germany. Nevertheless, due to the mixing of population, the sample contains male subjects from all German regions. The survey result is a random sample of 664 men with chest circumferences from $120 \mathrm{~cm}$ to $175 \mathrm{~cm}$.

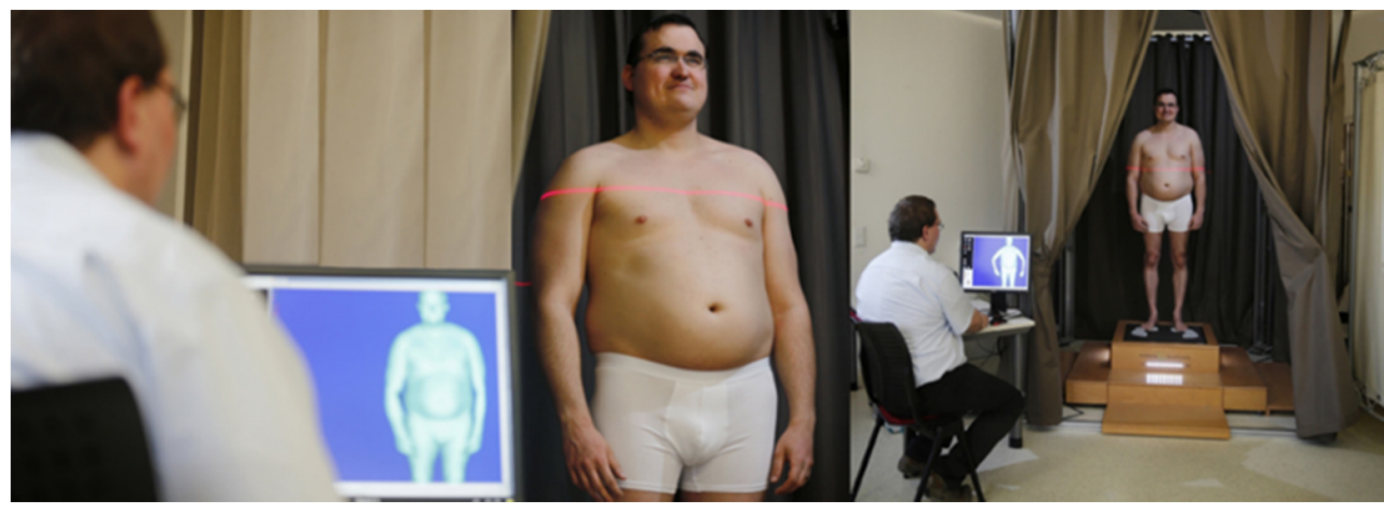

Fig. 2. Carrying out a size survey using 3D scanner technology

According to SizeGERMANY standards [2], subjects were scanned in three positions (see figure 3).
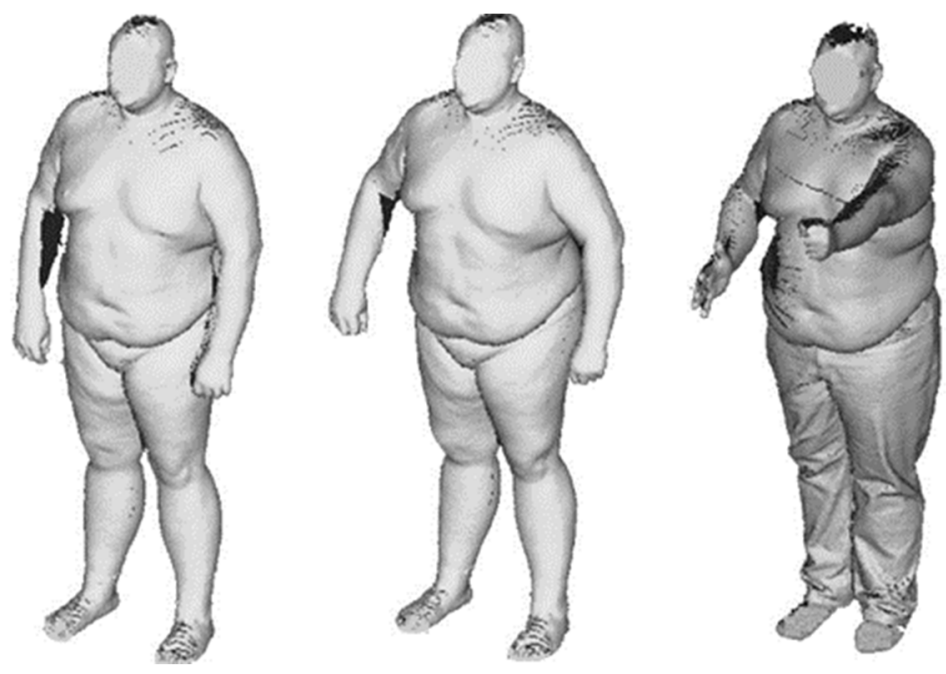

Fig. 3. Scanning positons within the R\&D project "Plus sizes men" 
The first position "relaxed" is corresponding to the common practice for manually measurement acquisition as well as to the posture while wearing everyday clothing. Second position "standard" allows capturing the body surface with the least shadowing, e.g. at thigh or upper arm region. Third posture "reach" is known from ergonomic research [8]. It was used to scan subjects in their own trousers aiming a 3D based fitting.

\subsection{Sizing system definition}

As a first step a new structure for the plus size charts had to be developed. Starting the project, there was no consistence basis due to the historical development of German men's outerwear size charts. Therefore, three research questions had to be clarified:

- To which men's outerwear sizing structure should the new charts be connected?

- What kind of interval of chest circumference should be the basis for the chart?

- What kind of increase of body height is reasonable to implement?

\subsubsection{Classification of men's outerwear}

SizeGERMANY 2009 [2] size charts (size 42 to 60) represent state of the art. Results of the statistical analyses proved that the SizeGERMANY classification can be applied on the plus sizes as well. However, one problem occurred. The increase of body height had to be modified.

\subsubsection{Interval of chest circumference}

In Germany assignment of garment sizes is based on chest circumference. For men's outerwear the size designation is half the value of the chest circumference, e.g. $100 \mathrm{~cm}$ chest girth is size 50 . Therefore, determination of the measurement interval is of fundamental importance. Market practice showed differing business solutions relating to plus sizes. At the time of the project start, a sizing standard was missing. Intervals of $4 \mathrm{~cm}, 6 \mathrm{~cm}$ up to $8 \mathrm{~cm}$ were used and sometimes even alternating. Even the DIN EN 13402-3 was revised [9], chest circumference was changed several times and there was no existing basis. Hence, new grading values had to be defined.

Within the project, interval of chest circumference was defined to be $4 \mathrm{~cm}$. The advantage was on the one hand the potential of detailed analyses of the sample's body measurements and on the other hand the opportunity to easily change the values to $6 \mathrm{~cm}$ or $8 \mathrm{~cm}$.

\subsubsection{Increase of body height}

One widely discussed issue in men's outerwear sector is weather a constant or an increasing body height is more reasonable, while chest circumference is increasing from size to size. In 1960s German men's outerwear size chart [10] the body height was increased $3 \mathrm{~cm}$ respectively $2 \mathrm{~cm}$ from size to size. Up to SizeGERMANY 2009 this was common practice. But it is well known, that increase of body height cannot be extended limitlessly. If followed this rule a person in size 82 would have a body height of $210 \mathrm{~cm}$. Obviously, this does not reflect reality. In SizeGERMANY sizing survey increase of body height was defined to be $1 \mathrm{~cm}$ per size. This is a feasible compromise between common practice and latest scientific findings.

Within the "plus sizes men" project the question about the perfect increase of body height got a final answer. Figure 4 is a scatter diagram showing chest circumference on the $x$-axis and body height on the $y$-axis. Each point is representing the body measurements of one individual subject. Apparently, there is no significant correlation between the two dimensions. The red trend line is horizontal without showing any increasing or decreasing tendency. The results prove clearly that the average body height is not increasing with increasing chest circumference. In addition, figure 4 emphasizes the necessity of five body height types because of the big variance of individuals. The body height classification - extra short (extra kurz), short (kurz), normal, long (lang), extra long (extra lang) was assumed from SizeGERMANY. 


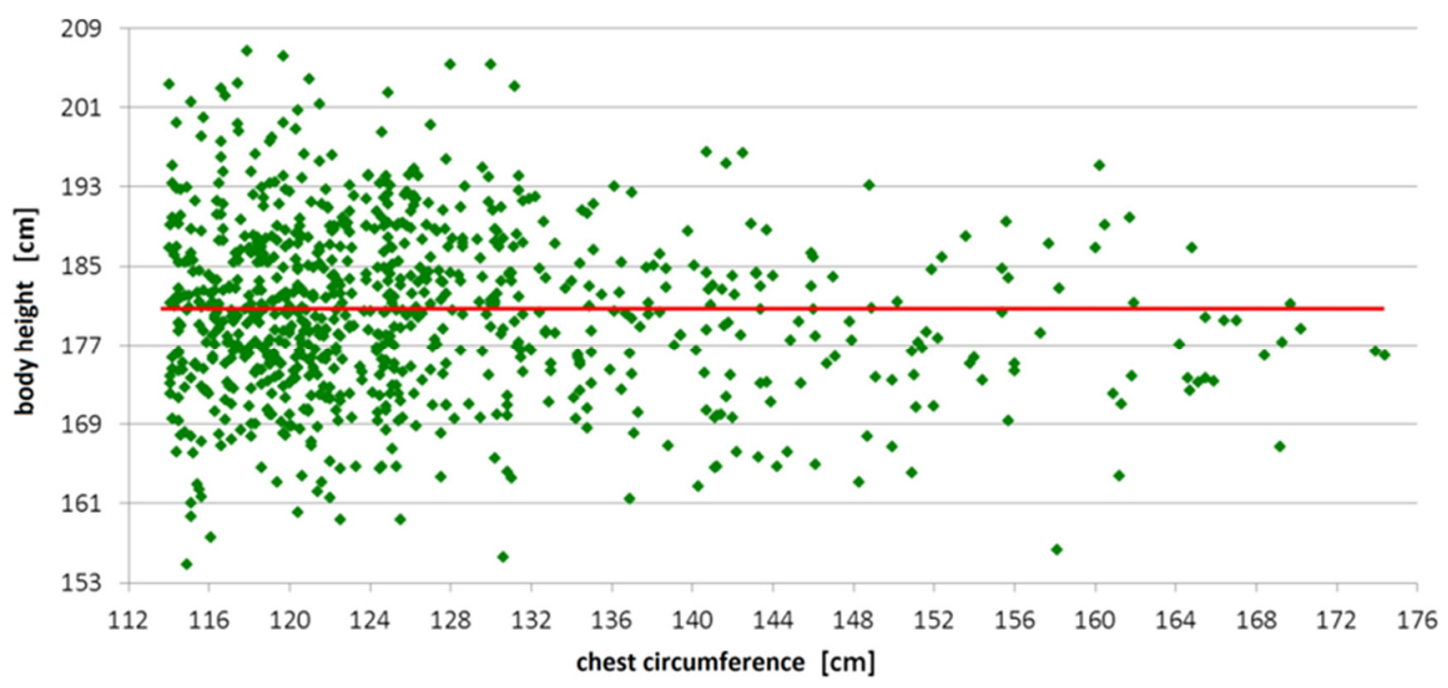

Fig. 4. Correlation analyses of body height and chest circumference starting form size 58

\subsubsection{Figure types}

The difference between chest circumference and waist circumference determines the figure type. The figure type designation is assumed from SizeGERMANY (see Figure 5): extra thin (xschlank), thin (schlank), normal, heavy (stark), extra heavy (xstark). The figure type is differentiated within the body height classifications.

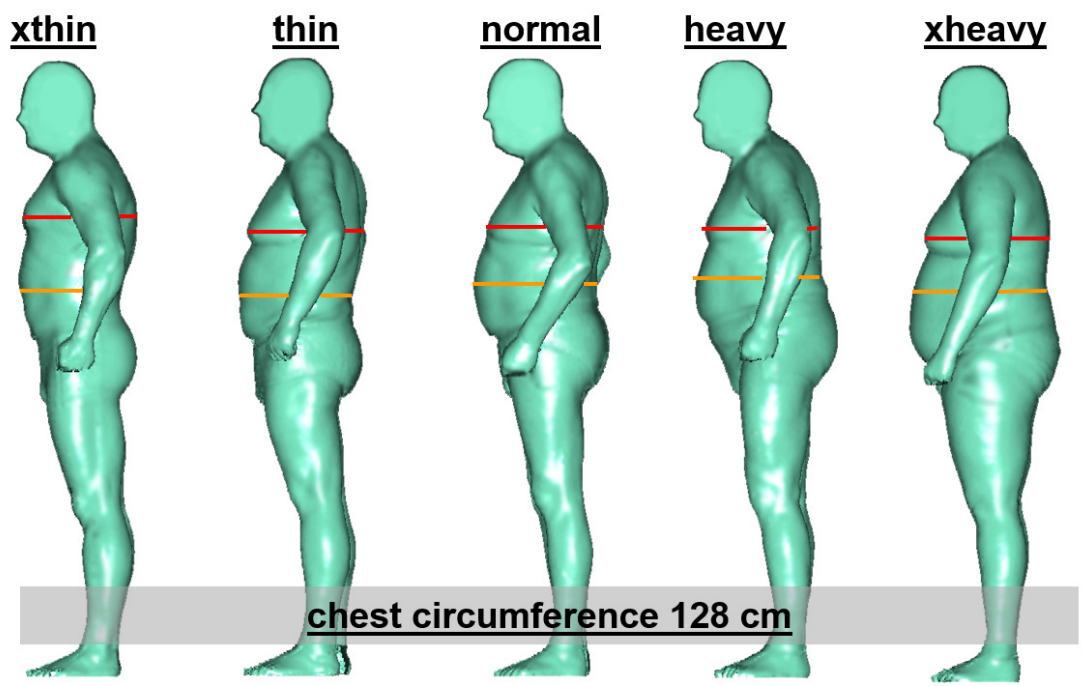

Fig. 5. Presentation of the five figure types each one with chest circumference $128 \mathrm{~cm}$

\subsection{Fundamentals of the „Plus size men“ sizing chart}

The fundamentals of the „Plus size men” sizing chart are 664 data sets of men with chest circumferences from $120 \mathrm{~cm}$ to $175 \mathrm{~cm}$. In addition 150 individual scans with chest circumference $116 \mathrm{~cm}+/-2 \mathrm{~cm}$ were integrated. From each scan 123 body measurements were taken with the aim to describe the average body in detail. According to ISO 8559 [12] and SizeGERMANY-standards [2], anthropometric landmarks and measurements were taken. Within the process of plausibility assessment, outlier were identified and erased. Therefore, a consistent data basis was available.

For body measurement analyses, it is of particular importance to take into account multidimensional correlations between lengths and circumferences [13]. The multidimensional evaluation was performed with software Origin $8 \mathrm{G}$. Figure 6 shows an example of a three-dimensional scatter diagram where again each point represents the measurements of one specific individual. It visualizes the existing correlations between chest circumference, waist circumference and body height. Again, it can be clearly seen, that there is no correlation between chest circumference and body height. 


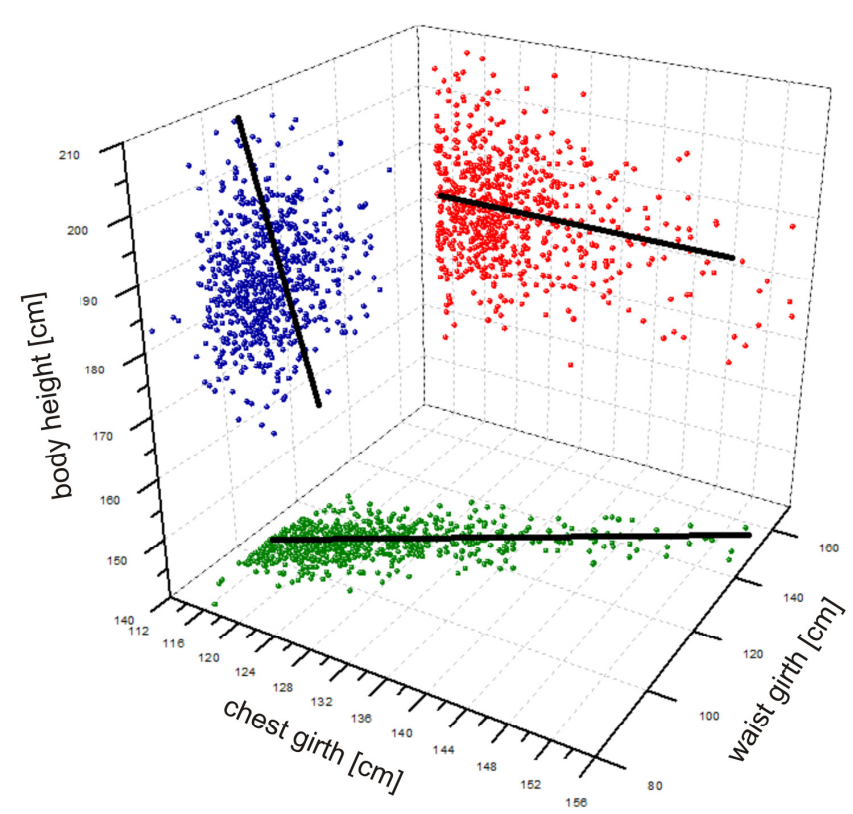

Fig. 6 Three-dimensional evaluation of the body measurements: body height chest and waist circumference

The statistic evaluation of body measurements combined with the 3D body shape analyses of individual body proportions is the basis for defining morphotypes (see chapter 3.2). Morphotypes that based on 3D body features help to identify size specific characteristics. 3D body form data is of vital importance to gain an optimized garment fit.

\subsection{Generation of virtual 3D body models}

Average 3D body models were developed on the basis of statistical evaluation as well as on the 3D shape analyzes. On the one hand they were the foundation of the size chart verification. On the other hand they were utilized to construct basic patterns on 3D basis (see chapter 2.5). Developing the 3D body models and the size chart in parallel ensures that the size charts match with the 3D body models and vice versa. Software Geomagic Studio 2012 was utilized to edit digital data and to generate 3D body models. Basic procedure was:

- Choosing a sufficient number of 3D scan data of a defined size cluster: Selection parameters were primary measurements as body height, chest circumference and waist circumference followed by secondary measurements in descending priority.

- Generating polygon models: Point cloud scan data was transferred into a polygon surface. Via triangulation the points were connected to triangle planes. Planes were orientated in one direction by rearrangement of surface normals. Entire scan surface was edited in several steps in order to generate a smoothed polygon model.

- Calculating average bodies on the basis of clustered 3D scans: Utilizing Geomagic Studio average bodies were calculated. Each body model was resulting out of 20 to 30 individual scans.

- Editing and shaping of average bodies to get watertight surfaces: Holes were filled and insufficient forms were adjusted, e.g. body parts underneath arms or legs.

- Determining the acceptable degree of idealization: Depending on the desired purpose each 3D body model was idealized, e.g. characteristics of the abdomen as form and base.

- Verifying the average 3D body models: Verification and adjustment of 3D body models was performed regarding measurement and form compliance relating to size charts.

- Final preparation of models: Mesh was checked regarding holes, gaps and overlaps. Extreme edge angles, overlaps and spikes were erased and edited.

\subsection{D based development of body compliant basic patterns for jackets and trousers}

Basic patterns with an optimized fit for jackets and trousers for plus sizes have been developed based on 3D data. New methods have been evolved. Idealized body surfaces of average 3D body models were transformed into a plane in order to derive 2D pattern geometry. This approach ensures the development of basic patterns with optimized fit because 3D body geometry can directly integrated in pattern pieces. [14] This principle is shown in figure 7 using a pair of trousers as an example. A 3D 
body model (left side) is the basis for body surface transformation into a plane. In a next step the surface is flattened by utilizing 3D software Rhinoceros 4.0. It is only possible to flatten NURBS planes (Non-Uniform Rational B-Spline) with unidirectional radii of curvature. Therefore, 3D planes are constructed on the polygon net to reproduce the body surface and the way clothes idealize body appearance (see figure $7,2^{\text {nd }}$ image from left side). To get consistent results by flattening differing body surfaces, the polygon net was segmented horizontally and vertically (see figure $7,3^{\text {rd }}$ image from left side). According to polygon net segments the 3D surface is enrolled and transformed into a plane. Then, segments are unraveled and rearranged into a first basic form (see figure $7,4^{\text {th }}$ image from left side). Finally the contour of the rearranged planes including all holes and overlaps is extracted. This DXF file is used in CAD systems as foundation for basic pattern development (see figure 7, right side) or as a pattern for test garments.
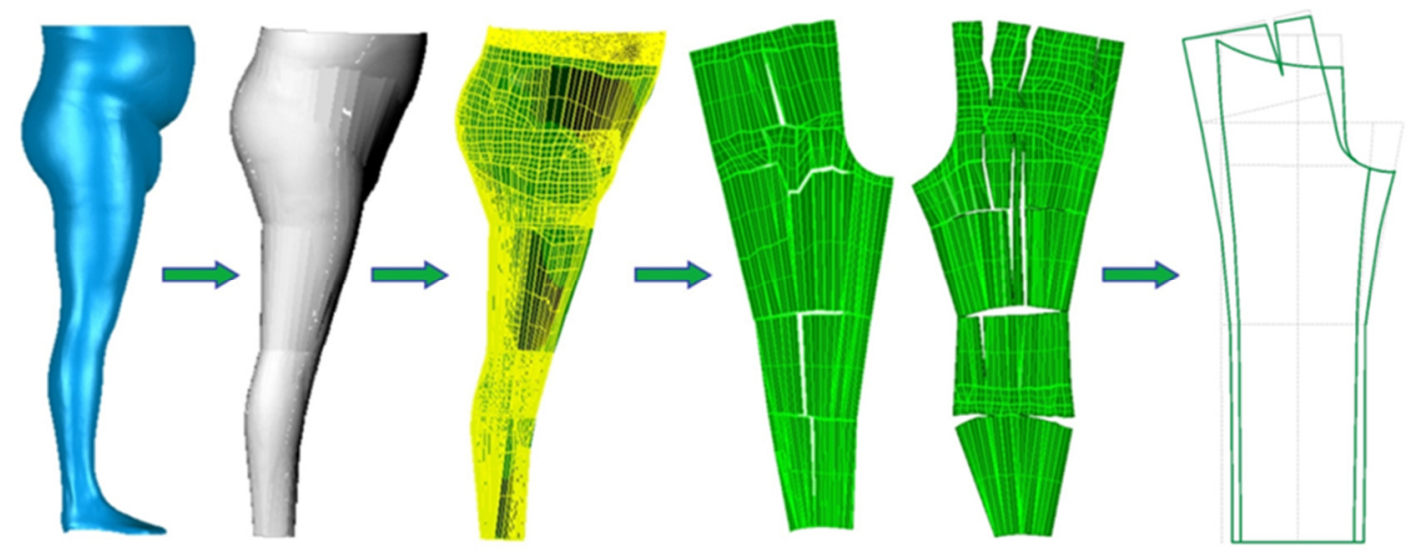

Fig. 7. Flattening and rearranging of constructed NURBS planes - e.g. trousers

\section{Results and Discussion}

\subsection{New size charts „Plus sizes men“}

For the first time body measurements of plus sizes men are available for German clothing industry. The size charts are related to SizeGERMANY systematics and include German sizes 60 to 78 in five body height types and five figure types. They contain six primary measurements and 42 secondary measurements as well as weight. In addition, target group specific body measurements like "Waistband circumference", "Waistband circumference below abdomen" and "Height of waistband circumference" analogous to waist circumference height (see figure 8) are provided.

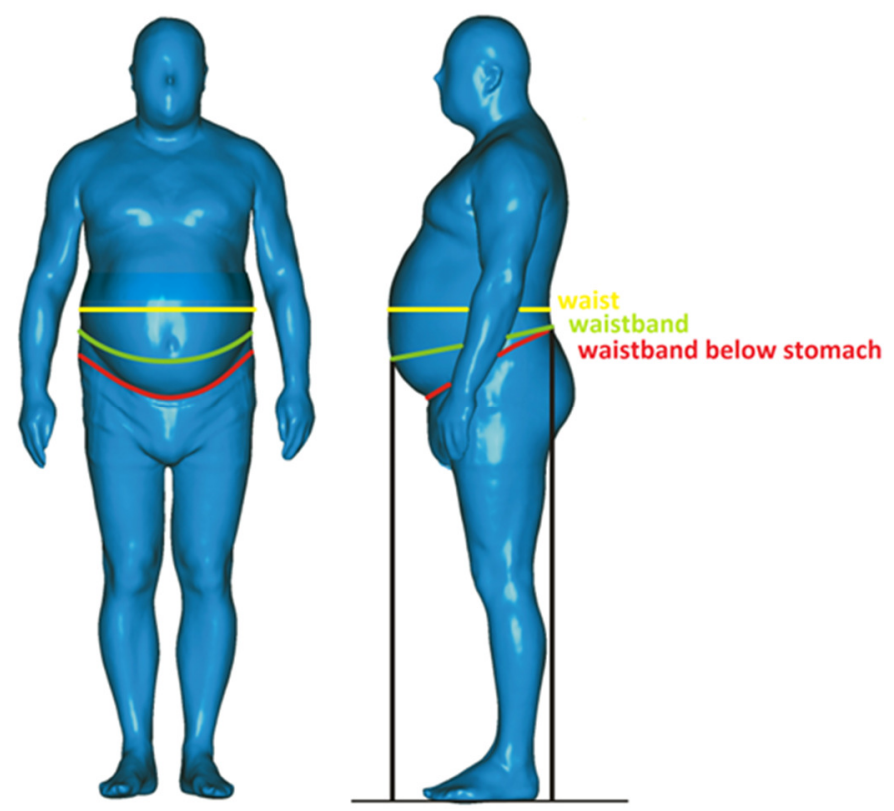

Fig. 8. Target group specific measurements „plus sizes men“ 
Horizontally waist circumference is unsuitable to take conclusions about the width and the real waistband position. Therefore, waistband circumference was defined as basic measurement for waistband width. This measurement is not available in standard sizing charts. And until this point there were no research findings. For detailed analyses of this issue, each subject was scanned in underwear and in its own trousers. Figure 9 shows a choice of subjects from side view. The red line marks the waist circumference which is obviously not linked to the waistband circumference. Waistband position is significantly lower than the traditional waist position. This has to be taken into account in pattern development. If not, trousers slip down and typical fitting problems or wrinkles will occur as shown in figure 9.
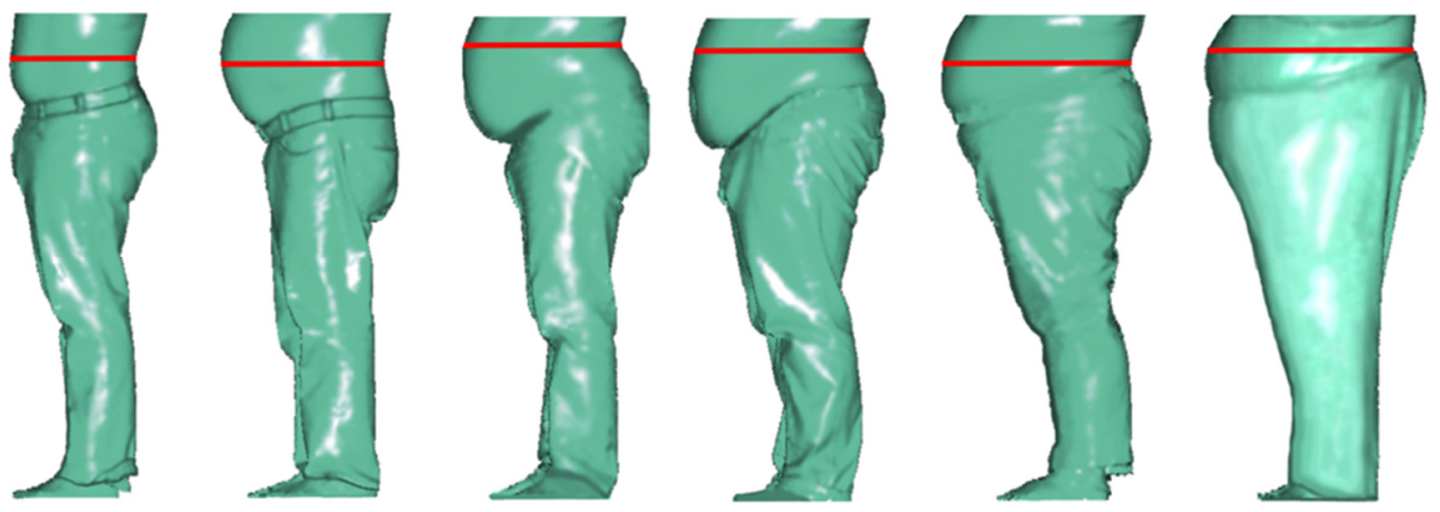

Fig. 9. 3D based fitting analyze - comparison of waist height and waistband height

\subsection{Definition of morphotypes}

One of the project objectives was the definition and specification of average body types considering body silhouettes and figure specific characteristics to derive representative morphotypes. Morphotypes are aim to identify size specific features and represent average body types. In contrast, classic figure types, e.g. thin, normal or heavy, are based on traditional measurements as lengths and circumferences. One of the most important men's body features determining the figure is the form of the abdomen (see figure 10).
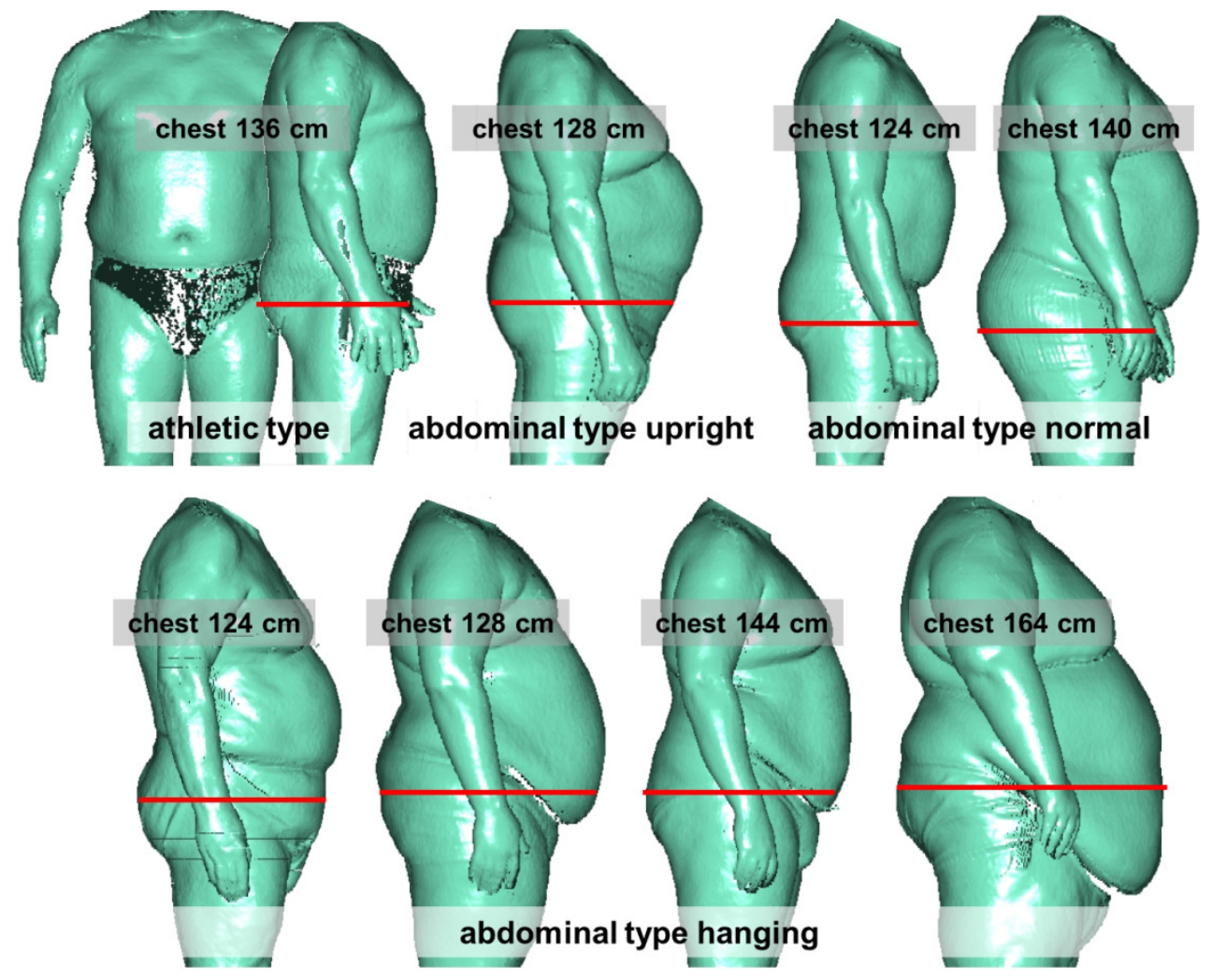

Fig. 10. Visualizing four abdomen types 
Four abdomen types were identified: the athletic type, the abdominal type upright, the abdominal type normal and the abdominal type hanging. Athletic types are men with large garment sizes only because of their large chest circumferences caused by chest muscles typical for specific sportsmen. Abdominal type upright describes bellies pointing upwards. Abdominal type normal characterizes belly forms that do not influence the hip circumference. Figure 10 shows hip circumference marked with a red line to emphasize that the hip circumference may be measured underneath the belly. Abdominal type hanging specifies men with a belly form influencing the hip circumference. This leads to a wide dispersion of the individual measurements.

\subsection{Representative 3D body models}

Following, the generated average 3D body models are illustrated. Each of them represents and visualizes the body measurements of the newly developed sizing chart. Figure 11 shows the average 3D models in German sizes 62, 66 und 70 in body height type „normal” and figure type „normal”

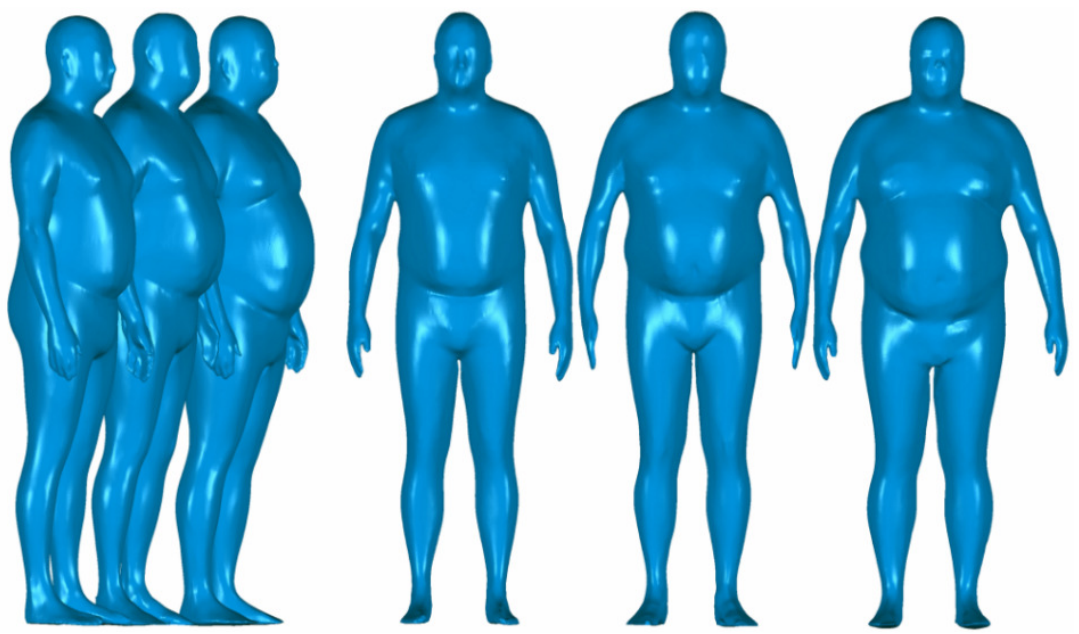

Fig. 11. Virtual 3D body models in the German sizes 62, 66 und 70

\subsection{Body compliant basic pattern for jackets and trousers}

\subsubsection{Basic pattern form for trousers}

Basic patterns for trousers were generated and examined. The 3D construction of the basic trousers' pattern shows that there is no necessity of a hip curve. The arrangement of the buttock seam length is in contrary to traditional basic construction rules. It is significantly longer at the front part and shorter at the rear part than generally known. This is mainly a result of the alignment to the body center regarding the vertical segmentation. Figure 12 shows the basic trousers' pattern in size 70 body height type „normal“ and figure type „extra heavy”.
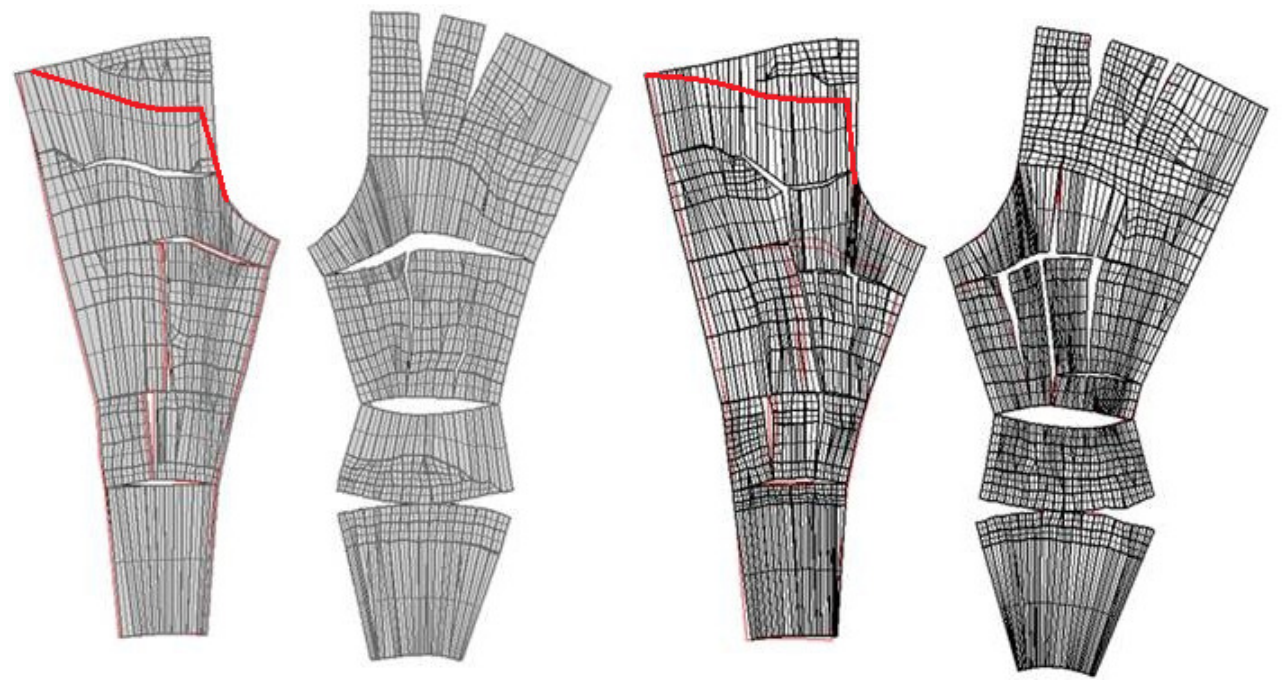

Fig. 12. Constructed basic trousers' pattern - size 70 „normal“ and "extra heavy“" 


\subsubsection{Basic pattern form for jackets}

Basic patterns for jackets were generated and examined. Figure 13 shows an average 3D body form of a torso in size 70 as well as the 3D planes idealizing the body surface. The planes bridge the belly base just as tight fitting garment would do. The alignment of the vertical segmentation was performed at the body center in side view. Hence, vertical segmentation may be compared to the side seam position (not repositioned).
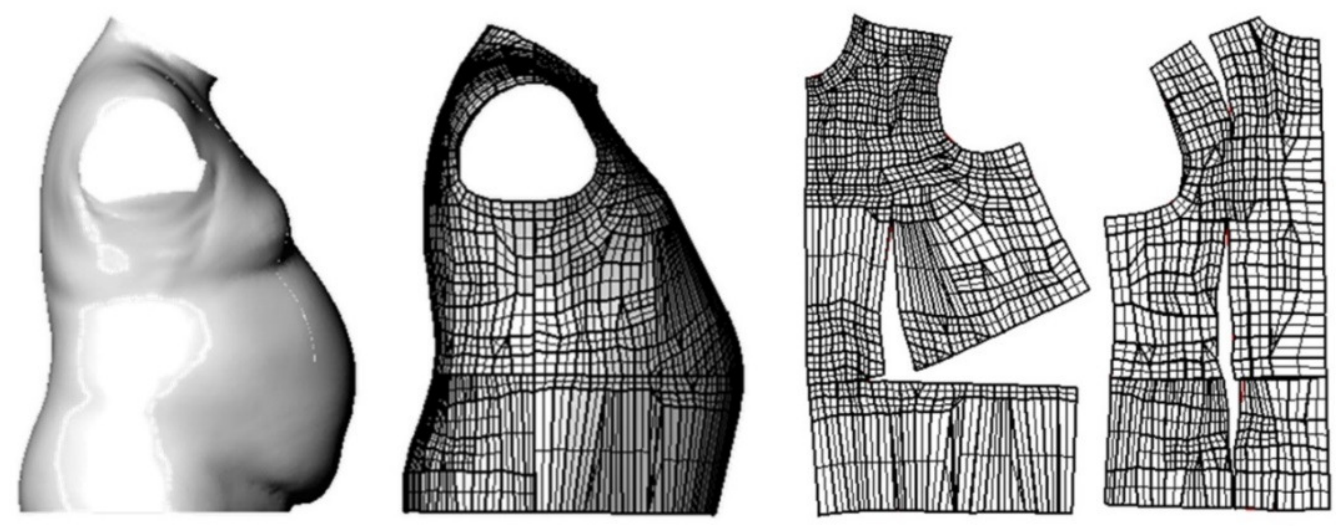

Fig 13. Average 3D body form and constructed 3D planes - size 70 „,normal“ and „extra heavy“

Particularly the large darts are to mention which are increasing from size to size. The belly dart is clearly larger than found in traditional basic constructions. The large chest and belly darts are necessary to get an optimized body form image. Furthermore, flattened planes show a nearly straight edge at center front. Common practice in traditional basic construction is a back part adjustment which could not be confirmed by research results of the flattened surface. Center back is perpendicular to the body axis.

\section{Conclusions}

For the first time body measurements and body shape information for the specific German target group of plus size men are available for clothing industry. The results of this research project provide a sustainable foundation regarding product development with optimized fit that are meeting the requirements of the target group.

The challenge was to generate a reasonable amount of target group body data which could not be realized in former sizing surveys. Because of the lack of data, producers and retailers had to make their own developments based on empiric processes. Therefore, two significant problems resulted. First, a company specific individual size interpretation occurred because of the lack of size standards. This led to a tremendous variance of sizes on the market regarding the plus sizes. Second, major fitting problems occurred. Garment products developed for "regular sizes" cannot be graded linearly to the big sizes because body dimensions for "regular sizes" cannot be extrapolated to the specific figures of plus sizes. The non-observance of the morphological characteristics leads unavoidable to fitting problems. The present results are closing the gap and are fostering a target group specific product development.

\section{Acknowledgment}

The IGF project $17460 \mathrm{~N}$ by the research association Forschungskuratorium Textil e.V., Reinhardtstraße 12-14, 10117 Berlin, is financed through the AiF within the framework of the program for promotion of cooperative industrial research (IGF) by the German Federal Ministry for Economic Affairs and Energy based on a resolution by the German Bundestag. 


\section{References}

[1] Bekleidungstechnisches Institut e.V., Forschungsinstitut Hohenstein, "Ergebnisse der HAKA-Reihenmessungen 1978/79 - Körpermaße und Marktanteile für Herren-Oberbekleidung", Haka-Treuhand GmbH (Ed.) Köln/Hohenstein, Germany, 1980.

[2] Human Solutions $\mathrm{GmbH}$ \& Hohenstein Institute, "SizeGERMANY", www.sizegermany.de, accessed 2016.

[3] H. Eberle et al., Fachwissen Bekleidung, Haan-Gruiten, Germany, 2013.

[4] N. Zakaria et al., "Apparel sizing: existing sizing systems and the development of new sizing systems, in Anthropometry, apparel sizing and design, D. Gupta, Ed. Cambridge, England, Woodhead Publishing, 2014, pp.3-33.

[5] A.C.K. Chan, "The development of apparel sizing systems from anthropometric data", in Anthropometry, apparel sizing and design, D. Gupta, Ed. Cambridge, England, Woodhead Publishing, 2014, pp.167-196.

[6] S. Morlock, E. Wendt, E. Kirchdörfer et al., "Grundsatzuntersuchung zur Konstruktion passformgerechter Bekleidung für Frauen mit starken Figuren", IGF 15144 BG, Bekleidungsphysiologisches Institut Hohenstein, Technische Universität Dresden, Boennigheim, Germany, 2009.

[7] S. Morlock, M. Harnisch et al., „Passformgerechte und bekleidungsphysiologisch optimierte Bekleidungskonstruktion für Männer mit großen Größen unterschiedlicher Körpermorphologien“, IGF 17460 N, Hohenstein Institut für Textilinnovation gGmbH, Boennigheim, Germany, 2015.

[8] ISO - International Organization for Standardization, "ISO 7250-1: Basic human body measurements for technological design-part 1: Body measurements definitions and landmarks", Genf, Swiss, 2008.

[9] DIN - Deutsches Institut für Normung e.V., „DIN EN 13402-3: Größenbezeichnung von Bekleidung Teil 3: Maße und Sprungwerte“, Berlin, Germany, 2014.

[10] Verband der Herrenbekleidungs-Industrie e.V. (HG.), "Größentabelle für Herren- und Knaben-Oberbekleidung" Köln, Germany, 1990 (Nachdruck).

[11] J. Chun, „International apparel sizing systems and standardization of apparel sizes“, in Anthropometry, apparel sizing and design, D. Gupta, Ed. Cambridge, England, Woodhead Publishing, 2014, pp.274-304.

[12] ISO - International Organization for Standardization, "ISO 8559: Garment construction and anthropometric surveys - body dimensions", Genf, Swiss, 1989.

[13] N.A. Schofield, „Pattern grading“, in S.P. Ashdown (Ed.), Sizing in clothing, Cambridge, England, Woodhead Publishing, 2007, pp.152-201.

[14] E. Kirchdörfer et al., "Entwicklung einer automatischen, körperkonformen Konstruktionssystematik für Oberbekleidung auf Basis von 3D-Körper-Informationen" IGF 15605 N, Hohenstein Institut für Textilinnovation e.V., Boennigheim, Germany, 2011. 